\title{
PREPARATION AND CHARACTERIZATION OF NITRENDIPINE LOADED GRAFTED COPOLYMER MICROSPHERES: A PRELIMINARY STUDY
}

\author{
SINDHU S*, DHARANI S, BHAVANITHA V, PRADHIBHA S
}

Department of Chemical Engineering and Materials Science, Amrita School of Engineering, Coimbatore, Amrita Vishwa Vidyapeetham, India. Email: s_sindhu@cb.amrita.edu

Received: 18 November 2017, Revised and Accepted: 14 May 2018

\begin{abstract}
Objectives: Developing countries like India suffers mostly from cardiovascular problems and kidney failure. An antihypertensive drug is mainly used to avoid the cardiovascular problems and kidney failure. Nitrendipine is a calcium antagonist widely used in the treatment of hypertension. The bioavailability of drug, when administered orally, is low. Sustained drug delivery systems are using microspheres emerging as an effective method to increase the bioavailability of the drug. The current work involves the encapsulation of nitrendipine - acrylamide grafted chitosan which helps to overcome poor solubility and hydrophobic nature of the nitrendipine. This will enhance the drug dissolution and reduce the side effects of the antihypertensive drug.
\end{abstract}

Methods: By emulsion cross-linking method, grafted copolymers were prepared. The physicochemical interactions between the drug and grafted copolymer were analyzed by scanning electron microscopy (SEM), Fourier-transform infrared spectroscopy (FTIR), and differential scanning calorimetry (DSC).

Results: Encapsulated drug and grafted copolymer were characterized by FTIR to understand the chemical interactions and to identify the functional groups present. Morphology and particle size of the grafted copolymer with drug and without drug were assessed by SEM. DSC was used to identify the melting endotherms of a drug, copolymer cross-linked microspheres, and drug encapsulated microspheres.

Conclusion: Thus, the drug encapsulated grafted copolymer increases the hydrophilic character and thereby making the polymers feasible for functioning as drug carriers for sustained drug delivery system.

Keywords: Nitrendipine, Chitosan, Microspheres, Graft copolymerization.

(C) 2018 The Authors. Published by Innovare Academic Sciences Pvt Ltd. This is an open access article under the CC BY license (http://creativecommons. org/licenses/by/4. 0/) DOI: http://dx.doi.org/10.22159/ajpcr.2018.v11i9.23733

\section{INTRODUCTION}

In most of the countries, hypertension considers being an important public health problem due to its impact on the society. Cardiovascular, cerebrovascular, and renal complications mainly occur due to pressure variation. For managing the hypertension problem, a large number of national and international guidelines have been published. In addition to diuretics, recently, the Joint National Commission guidelines suggested that both calcium channel blockers as well as angiotensinconverting enzyme inhibitors considered to be the best drugs [1].

To reduce the cardiovascular disease related to hypertension, calcium channel blockers considered to be an effective antihypertensive drug compared to the other antihypertensive drugs. Calcium channel blockers also used to prevent stroke [2]. Combination of calcium channel blockers with other antihypertensive drugs reduces the blood pressure efficiently [3].

The drug delivery system plays an important role for the proper release of active pharmaceutical ingredient inside the human body to obtain a good treatment effect. To treat the diseases, sustained drug delivery systems are gaining importance nowadays. These delivery systems provide an alternative to parenteral drug delivery system. These include liposomes, proliposomes, microspheres, gels, prodrugs, cyclodextrins, and among others. Microsphere-based sustained drug delivery system will provide a suitable alternative to reduce the side effects and increase the dissolution rate of the drug. Angadi et al. 2010 observed the controlled release (CR) of an isoniazid drug with the grafted copolymer microspheres cross-linked with glutaraldehyde (GA). Polymers blend microspheres were prepared by the water-in-oil emulsion technique for the sustained release of drug 5-fluorouracil [4]. Phadke et al. 2015 prepared the novel pH-sensitive microspheres with the grafted copolymer for the sustained release of drugs.

In the current situation, daily intake of nitrendipine, a waterinsoluble antihypertensive drug in the oral tablet form is $20 \mathrm{mg}$ [5]. This amount reduces the blood pressure by $15-20 \%$ within $1-2 \mathrm{~h}$ of administration [5]. Nitrendipine has oral bioavailability between $10 \%$ and $20 \%$ because of high first-pass metabolism. CR of drugs using polymers is a well-established technology. This technology is mainly used to encapsulate drug with the polymers and the release of drug from the polymer matrix takes place in a predetermined manner [6-8]. Recently, many researchers considered micro/nanoparticles derived from the biopolymers as the potential drug delivery devices compared to the conventional type dosage forms $[9,10]$.

Hydrophilic matrices have the capability to control the release of drug over an extended period. Hydrophilic polymers are frequently used for the sustained release of drugs. Recently, natural polymers, because of its low cost and extensive sources, have been receiving considerable attention. Chitosan (CS), a natural polymer obtained through alkaline deacetylation of chitin. Due to the hydrophilicity and biocompatibility of the polymer, it finds application in various fields [8,11]. High water retention property of acrylamide (AAM) made it suitable for its usage as biomaterials. They have been extensively used for biomedical applications, such as drug delivery systems [12]. Here, we considered two hydrophilic biodegradable polymers CS and AAM.

Therefore, the objective of the work is to discuss the encapsulation of the drug with the hydrophilic grafted copolymer for the sustained 
release of nitrendipine. This is the preliminary study attempted first on the usage of CS grafted AAM copolymer for the nitrendipine, an antihypertensive drug.

\section{METHODS}

Nitrendipine was purchased from Sigma Aldrich, India. CS, AAM, acetic acid, potassium persulphate, acetone, polyvinyl alcohol, light liquid paraffin, hydrochloric acid $(\mathrm{HCl}), \mathrm{n}$-hexane, and glycine were purchased from Techcraft solutions, India. Span 80 and GA used were purchased from Modern Scientific Company, India. Water used was deionized and double distilled. All the chemicals used were of AR grade.

\section{Preparation of copolymer}

Graft copolymerization of CS with AAM was carried out at different ratios 1:3, 1:5, and 1:7. In $160 \mathrm{ml}$ of $4 \%$ acetic acid solution, $2 \mathrm{~g}$ of CS was dissolved [13]. Then, a solution of $14 \mathrm{~g}$ of AAm in double-distilled and deionized water was added, where the ratio of CS and AAm is 1:7. The initiator potassium persulfate was added to the mixture and the mixture was stirred at room temperature for $1 \mathrm{~h}$. Then, the solution was taken in a reaction flask and it was further heated in thermostat water bath at $60^{\circ} \mathrm{C}$ for $2 \mathrm{~h}$. After that, it was cooled to the ambient temperature followed by the addition of excess amount of acetone for precipitation. The insoluble product was filtered. Then, the filtered product was vacuum dried at $40^{\circ} \mathrm{C}$. The grafting $\%$ was calculated using the following equation,

Grafting $\%=\frac{\mathrm{W}_{g}-\mathrm{W}_{o}}{W_{o}} * 100$

where $\mathrm{w}_{\mathrm{o}}$ and $\mathrm{w}_{\mathrm{g}}$ denote the mass of the CS and grafted CS with AAM

\section{Extraction of homopolymer of AAM}

During the grafting process, the formation of homopolymer may be possible. Soxhlet Extractor was used to remove the homopolymer formed during the reaction. The solution mixture of acetone-water was used in the extractor for $30 \mathrm{~h}$ to remove the homopolymer from the precipitate.

\section{Preparation of blend microspheres}

Equal amounts of grafted copolymer and polyvinyl alcohol (PVA) were added with double distilled deionized water to form the $20 \mathrm{ml}$ of $6 \%$ $(\mathrm{w} / \mathrm{v})$ polymer solution [13]. A small volume of alcohol was added to this mixture and stirred it to get the homogeneous solution. Light liquid paraffin containing $1 \%(\mathrm{w} / \mathrm{w})$ Span 80 was slowly added to emulsify the solution under constant stirring. To crosslink the matrix, GA was added along with $\mathrm{HCl}$ after $10 \mathrm{~min}$. For the complete formation of microspheres, the mixture was stirred continuously for $2 \mathrm{~h}$ and rigid microspheres were filtered. Suitable solvent was used to remove light liquid paraffin and Span 80 from the formed microspheres. Microspheres were again washed with glycine and water simultaneously to remove the inactive GA. Then, they were dried at low pressure for $24 \mathrm{~h}$ at $40^{\circ} \mathrm{C}$.

\section{Fourier-transform infrared spectroscopy (FTIR)}

FTIR of chitosan-grafted-acrylamide (CS-g-AAm) grafted copolymer microspheres and drug-encapsulated CS-g-AAm microspheres were measured using Thermo Nicolet is 10 FTIR spectrometer. FTIR spectra of samples were analyzed between the wavelength of 500 and 4000 $\mathrm{cm}^{-1}$ using $\mathrm{KBr}$ pellets at room temperature.

\section{Scanning electron microscopy (SEM)}

Images of SEM were recorded using a scanning electron microscope to examine the surface morphology of the empty microspheres of grafted copolymer cross-linked with GA and drug-loaded microspheres of grafted copolymer cross-linked with GA. The microspheres of grafted copolymer and drug encapsulated grafted copolymer microspheres were deposited on a brass holder and sputtered with a thin coating of gold, under vacuum. At room temperature with appropriate magnification, the SEM image was observed.

\section{Differential scanning calorimetry (DSC)}

DSC was used to measure the amount of heat absorbed or released during physical transformation such as phase transitions. Nitrendipine, CS grafted AAM cross-linked microspheres, and drug encapsulated grafted copolymer microspheres were analyzed by DSC Q20 V24.10 Build 122 at a heating rate of $10^{\circ} \mathrm{C} / \mathrm{min}$ from 0 to $400^{\circ} \mathrm{C}$ under a constant flow of nitrogen gas.

\section{RESULTS AND DISCUSSION}

\section{Grafting \%}

Free-radical polymerization reaction was obtained in the presence of potassium persulfate for graft copolymerization of CS-g-AAm. The complex formation between $-\mathrm{NH}_{2}$ and $-\mathrm{OH}$ groups of $\mathrm{CS}$ decomposed to generate the free radical sites at $60^{\circ} \mathrm{C}$. This facilitates the reaction site on the CS backbone for AAm monomer. At three different monomer concentration used in this study as shown in Table 1, grafting percentage of $90.96 \%$ was obtained for the $1: 7$ ratio of CS and AAM. This ratio was used for further preparation.

\section{Preparation of microspheres}

PVA was blended with the grafted product of 1:7 and microspheres were prepared. To stimulate the active groups of grafted CS, PVA mixed with grafted copolymer. Then, only crosslinking with GA should be effective. Sodium alginate coating was used to improve the hydrophilic nature of microspheres. Many researchers [4,13-19] obtained the similar results and the formed microspheres were used as the controlled drug release devices.

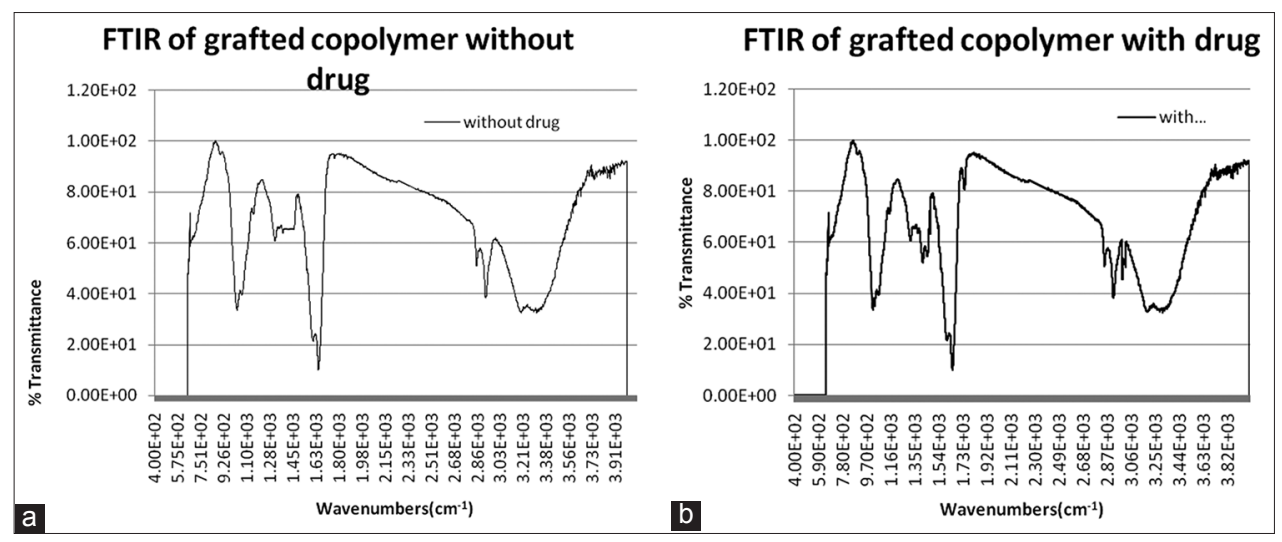

Fig. 1: (a) Fourier-transform infrared spectroscopy (FTIR) of grafted copolymer microspheres. (b) FTIR of drug encapsulated grafted copolymer microspheres 


\section{FTIR}

From the IR spectra, the characteristic peak around 3312 and 2922 $\mathrm{cm}^{-1}$ corresponds to the stretching of $\mathrm{O}-\mathrm{H}$ and aliphatic $\mathrm{C}-\mathrm{H}$ group of CS. CS grafted AAM shows the additional peak at $3193 \mathrm{~cm}^{-1}$ denotes the bonded $\mathrm{NH}$ stretching vibrations and antisymmetric $\mathrm{NH}$ bonding at $1653^{-1}$ due to the primary amides. From these spectra, we conclude that AAM grafted properly on the CS as shown in the Fig. 1a. In the IR spectra of the nitrendipine encapsulated CS grafted AAM copolymer as shown in the Fig. 1b. The peak at $2970 \mathrm{~cm}^{-1}$ specifies the $\mathrm{CH}$ stretching and the peak formed between 1700 and $1720 \mathrm{~cm}^{-1}$ denotes the carbonyl ester vibration. The principal peaks for nitrendipine appeared between 1020 and $1329.56 \mathrm{~cm}^{-1}$ indicate the presence of carboxyl and carboxylate groups as well as NO group between 1349.56 and $1500.34 \mathrm{~cm}^{-1}$. Similar results were obtained for the drug encapsulated microspheres with different polymers [15].

Table 1: \% Grafting of different ratios of grafted copolymer

\begin{tabular}{llll}
\hline $\begin{array}{l}\text { Type of } \\
\text { CS-g-AAm }\end{array}$ & $\begin{array}{l}\text { Mass of } \\
\text { CS } \mathbf{~ g ) ~}\end{array}$ & $\begin{array}{l}\text { Mass of } \\
\text { AAm }(g)\end{array}$ & $\begin{array}{l}\text { \% } \\
\text { Grafting }\end{array}$ \\
\hline P1 & 1 & 3 & 68.9 \\
P2 & 1 & 5 & 52.6 \\
P3 & 1 & 7 & 90.96 \\
\hline
\end{tabular}

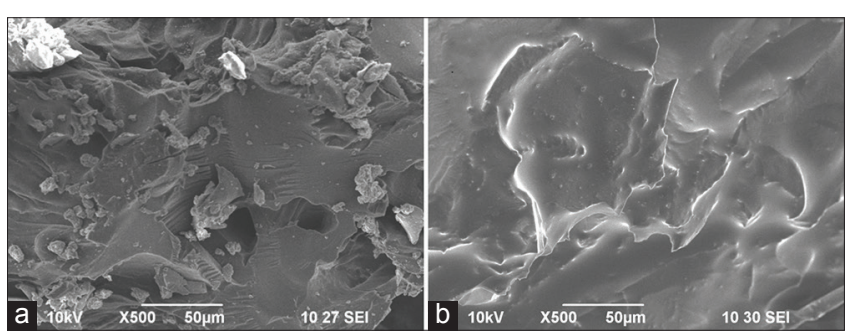

Fig. 2: Scanning electron microscopy image of the (a) surface of the empty microspheres and (b) surface of the drug-loaded microspheres

\section{SEM}

Shape and surface morphology of the microsphere formation were conformed from the SEM images. SEM image of the surface of the empty microspheres and surface of the drug-loaded microspheres is shown in the Fig. 2a and 2b. Smooth surface was observed in the empty grafted copolymer cross-linked microspheres as shown in the Fig. 2a, whereas nitrendipine loaded microspheres showed an irregularity in the surface as shown in the Fig. 2b. For the controlled release of Nitrendipine microspheres loaded with different polymers and additives,Nifedipine interpenetrating network microsphere blended with grafted copolymers, Theophylline and isoniazid IPN microspheres encapsulated with hydrophilic polymers and chitosan sodium alginate carbamazepine microspheres shows a smooth surface and rough surface for the unloaded and drug loaded microspheres[13-20]. From the result, we observed that the formed microsphere is suitable for the sustained release studies.

DSC

As shown in the Fig. 3a, the sharp endothermic peak at $158.61^{\circ} \mathrm{C}$ indicates the presence of a crystalline form of the drug. The glass transition temperature of CS grafted AAM increased to $219^{\circ} \mathrm{C}$ with respect to the pure CS due to the increase in the AAM chain length of the polymer as shown in the Fig. 3b [13]. No peak was observed at the endothermic peak of nitrendipine as shown in the Fig. 3c of nitrendipine loaded microspheres. From this, we observed that amorphous form of drug exist in the microspheres and it was dispersed in the grafted copolymer. Rokhade et al. observed a sharp peak at $277^{\circ} \mathrm{C}$ from the DSC of theophylline which indicates the melting of the drug. For the drugloaded microspheres, due to endothermic transitions, three peaks were observed at $41^{\circ} \mathrm{C}, 74^{\circ} \mathrm{C}$, and $181^{\circ} \mathrm{C}$ from the DSC. No peak was observed at $277^{\circ} \mathrm{C}$ which represents the amorphous dispersion of theophylline into matrix [19]. Similarly, Angadi et al. obtained the DSC thermogram for placebo, drug, and drug-loaded microspheres [18]. Fude et al. and Basu et al. obtained the sharp peak from DSC for the pure drug, drug loaded with polymer showed the peak at various temperature which shows the dispersion of the drug $[15,20]$. From this preliminary study, we observed that grafted copolymer encapsulated with drug will be suitable for the sustained release of drugs compared with the existing literature $[15-17,20]$.

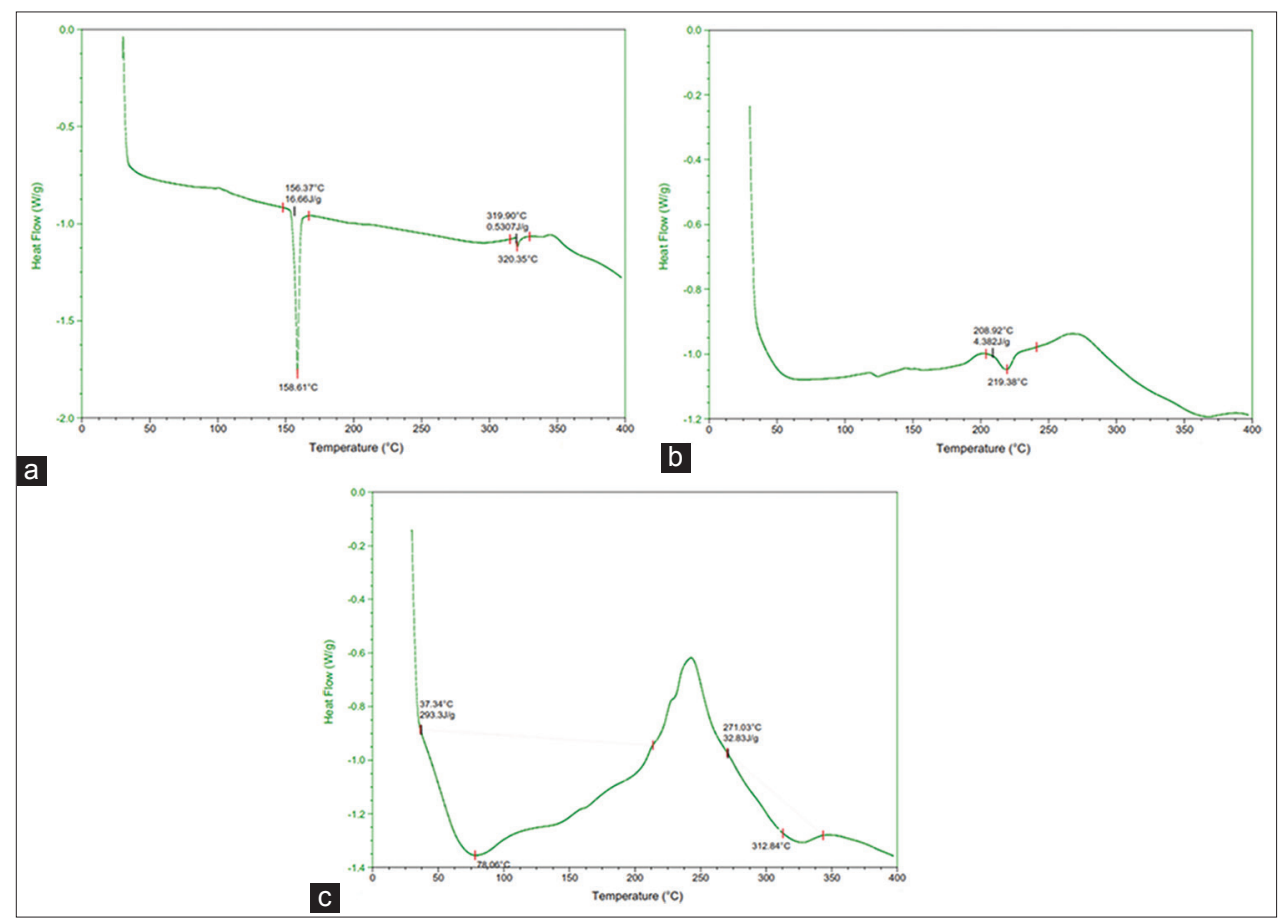

Fig. 3: (a) Differential scanning calorimetry (DSC) curve of pure nitrendipine drug. (b) DSC curve of grafted copolymer microspheres. (c) DSC curve of drug encapsulated grafted copolymer microspheres 


\section{CONCLUSION}

Emulsion cross-linking method was used to prepare microspheres from grafted copolymer mixed with PVA and cross-linked with GA. From the characterization, we conclude that drug properly encapsulated with grafted copolymers in the form of microspheres. This drug encapsulated copolymer should be used for the sustained release of drugs. Drug release studies have to be carried out for the obtained microspheres by varying the amount of polymer, cross-linking agent, and drug.

\section{ACKNOWLEDGMENTS}

This work was supported by the Department of Chemical Engineering \& Materials Science, Amrita University, Coimbatore.

\section{CONFLICTS OF INTEREST}

All authors have none to declare.

\section{REFERENCES}

1. Jarari N, Rao N, Peela JR, Ellafi KA, Shakila S, Said AR, et al. A review on prescribing patterns of antihypertensive drugs. Clin Hypertens 2015;22:7.

2. Law MR, Morris JK, Wald NJ. Use of blood pressure lowering drugs in the prevention of cardiovascular disease: Meta-analysis of 147 randomised trials in the context of expectations from prospective epidemiological studies. BMJ 2009;338:b1665-b1665.

3. Wald DS, Law M, Morris JK, Bestwick JP, Wald NJ. Combination therapy versus monotherapy in reducing blood pressure: Meta-analysis on 11,000 participants from 42 trials. Am J Med 2009;122:290-300.

4. Reddy LC, Reddy RS, Rao KK, Subha MC, Rao CK. Development of polymeric blend microspheres from chitosan-hydroxypropylmethyl cellulose for controlled release of an anti-cancer drug. J Korean Chem Soc 2013;57:439-46

5. Siddiqui MA, Plosker GL. Fixed-dose combination enalapril/ nitrendipine a review of its use in mild-to-moderate hypertension. Drugs 2004;64:1135-48

6. Banker GS, Rhodes CT. Modern Pharmaceutics. $3^{\text {rd }}$ ed. New York: M. Dekker Publishers; 1996.

7. Sreekumaran AN, Vidhya KM, Saranya TR, Sreelakshmy KR, Nair SC. Mucoadhesive buccal patch of Cefixime trihydrate using biodegradable natural polymer. Int J Pharm Pharm Sci 2014;6:366-71.

8. Nair SC, Anoop KR. Local antimicrobial delivery of satranidazole loaded cross linked periodontal chips using bio degradable polymers. Int J Pharm Pharm Sci 2013;5:839-47.

9. Soppimath KS, Kulkarni AR, Aminabhavi TM. Chemically modified polyacrylamide-g-guar gum-based crosslinked anionic microgels as $\mathrm{pH}$-sensitive drug delivery systems: Preparation and characterization. J Control Release 2001;75:331-45.

10. Agnihotri SA, Mallikarjuna NN, Aminabhavi TM. Recent advances on chitosan-based micro- and nanoparticles in drug delivery. J Control Release 2004;100:5-28.

11. Li K, Wang Y, Huang M, Yan H, Yang H, Xiao S, et al. Preparation of chitosan-graft-polyacrylamide magnetic composite microspheres for enhanced selective removal of mercury ions from water. J Colloid Interface Scic 2015;455:261-70.

12. Pathania D, Gupta D, Agarwal S, Asif M, Gupta VK. Fabrication of chitosan-g-poly(acrylamide)/CuS nanocomposite for controlled drug delivery and antibacterial activity. Mater Sci Eng C 2016;64:428-35.

13. Phadke KV, Manjeshwar LS, Aminabhavi TM. Novel pH-sensitive blend microspheres for controlled release of nifedipine - An antihypertensive drug. Int J Biol Macromol 2015;75:505-14

14. Ramesh K, Krishnapriya M, Paul A, Nair SC. Preparation and evaluation of chitosan sodium alginate carbamazepine microspheres. Asian J Pharm Clin Res 2017;10:5-10.

15. Basu SK, Adhiyaman R. Preparation and characterization of nitrendipineloaded eudragit RL 100 microspheres prepared by an emulsion-solvent evaporation method. Trop J Pharm Res 2008;7:1033-41.

16. Yang MS, De CF, You BG, Fan YL, Wang L, Yue P, et al. Preparation of sustained-release nitrendipine microspheres with eudragit RS and aerosil using quasi-emulsion solvent diffusion method. Int J Pharm 2003;259:103-13.

17. Yang M, Cui F, You B, You J, Wang L, Zhang L, et al. A novel $\mathrm{pH}$-dependent gradient-release delivery system for nitrendipine: I. Manufacturing, evaluation in vitro and bioavailability in healthy dogs. J Control Release 2004;98:219-29.

18. Angadi SC, Manjeshwar LS, Aminabhavi TM. Interpenetrating polymer network blend microspheres of chitosan and hydroxyethyl cellulose for controlled release of isoniazid. Int J Biol Macromol 2010;47:171-9.

19. Rokhade AP, Shelke NB, Patil SA, Aminabhavi TM. Novel interpenetrating polymer network microspheres of chitosan and methylcellulose for controlled release of theophylline. Carbohydr Polym 2007;69:678-87.

20. Fude C, Mingshi Y, Yanyan J, Dongmei C, Wenhui L, Yuling F, et al. Design of sustained-release nitrendipine microspheres having solid dispersion structure by quasi-emulsion solvent diffusion method. J Control Release 2003;91:375-84. 